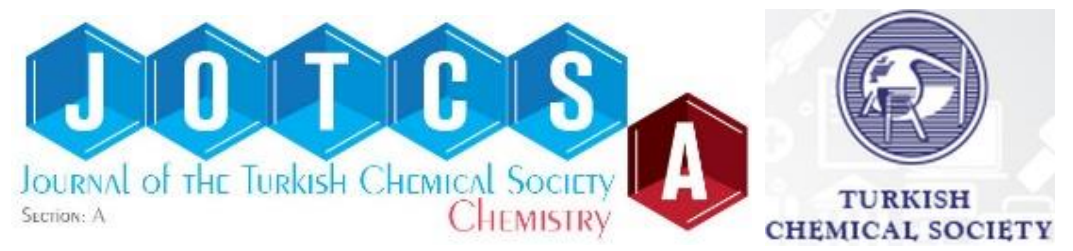

\title{
Synthesis of 2,3-Dihydroxypropyl-Sulfanyl Derivative Nonionic Surfactants and Their Inhibition Activities Against Carbon Steel Corrosion in Acidic Media
}

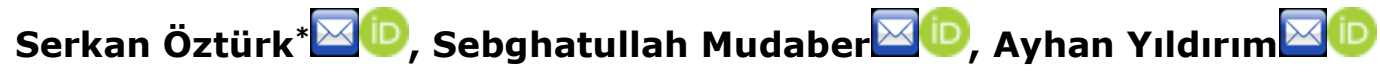 \\ Uludağ University, 16059, Bursa, Turkey
}

\begin{abstract}
In the present study, various amide-based, sulfur-containing nonionic surfactants were synthesized and characterized by spectroscopic methods. The corrosion inhibition properties of these synthesized compounds were investigated. For this purpose, mild steel coupons were immersed for 24 hours at room temperature in $1 \mathrm{M} \mathrm{HCl}$ containing different concentrations of inhibitor according to the standard method. As a result of these corrosion tests, the synthesized compounds exhibited excellent inhibitory properties (76.58-93.74 IE\%). Surface characterization studies were also performed for the metal coupons to support the obtained corrosion inhibition efficiency results.
\end{abstract}

Keywords: Metal corrosion, non-ionic surfactant, acidic medium, SEM.

Submitted: April 27, 2017. Accepted: February 05, 2018.

Cite this: Öztürk S, Mudaber S, Yıldırım A. Synthesis of 2,3-Dihydroxypropyl-Sulfanyl Derivative Nonionic Surfactants and Their Inhibition Activities Against Carbon Steel Corrosion in Acidic Media. JOTCSA. 2018;5(2):333-46.

DOI: http://dx.doi.org/10.18596/jotcsa.309423.

*Corresponding author. E-mail: serkanozturk@uludag.edu.tr. 


\section{INTRODUCTION}

Corrosion is the change of physical, chemical and mechanical properties of materials as a result of chemical and electrochemical reactions with the influence of environment (1). If the content consists of metals and alloys, then it can be used as metal corrosion and can be defined as corrosion of metal or metal alloys by oxidation or other chemical effects. Metallic corrosion is one of the most critical problems in various industrial fields. It is an undesirable phenomenon, causing economic loss for every country. As a result of corrosion, a significant portion of iron and steel is lost annually or becomes unusable. The metal, which is lost after the corrosion, causes economic losses at much higher cost than its value. On the other hand, corrosion losses affect not only the iron and steel industry but also the efficiency of all the investments being made by utilizing this sector, and it is a topic that interests the country's economy. Corrosion is also a cause of damage to human life and health and environmental pollution as well as material losses.

The corrosion phenomenon in the metals consists of two electrochemical reactions that proceed in the same way as oxidation in the anode and reduction in the cathode. Elements inducing to corrosion (metal, anodic reaction, cathodic reaction, and electrolyte) must be in one piece for the formation of metallic corrosion at the electrode/electrolyte interface, which is called the electrical interface.

Acid cleaning (pickling), which is a useful surface cleaning method, is frequently used in the industry to clean the rust and foreign materials on the metal surface. The most commonly used acids in this cleaning process are $\mathrm{HCl}$ and $\mathrm{H}_{2} \mathrm{SO}_{4}$ solutions (2). During the cleaning process with acid, metal corrosion occurs on the metal surface over time. In the cathode reaction of the metal corrosion in the acidic medium, hydrogen ions from the acid are reduced to form the $\mathrm{H}_{2}$ gas. One of the most effective methods to deal with metallic corrosion in the acidic environment is to design and use appropriate organic corrosion inhibitors. A corrosion inhibitor is a substance that significantly reduces corrosion rate when added at low concentrations.

Investigations made in recent years have discovered that surfactants can be used as inhibitors against metal corrosion. High corrosion inhibition efficiency at low concentrations, lower toxicity, easy and economical price production are being the advantages of using a surfactant as corrosion inhibitor (3). In particular, it has been proven in scientific studies that non-ionic surfactants, where the polar head group is without charge, that known to have many applications throughout industry, including cosmetics, detergents, are useful inhibitors against metal corrosion in acidic environments (4-10). It is understood that non-ionic surfactants can adsorb onto the metal surface and therefore reduces anodic dissolution, and retards the hydrogen evolution reaction (9). The nonionic surfactants can also be mixed with other types of surfactants, e.g., anionic or 
cationic, to enhance their properties and increase their inhibition activities against metal corrosion $(9,10)$. In the literature, it is also reported that nonionic surfactant increases the inhibitory activity of the amino acid derivative by synergistic effect (11).

In this study, (2,3-dihydroxypropyl) sulfanyl derivatized three nonionic surfactants containing high carbon chained amide functional group were synthesized, and their corrosion inhibition efficiencies against metallic corrosion in the acidic medium were investigated.

\section{MATERIALS AND METHODS}

\section{Materials and Instrumentation}

Reagents and solvents were purchased from Merck (Germany). Thermo Nicolet 6700 FT-IR spectrometer was used for acquisition of the FT-IR spectra. ${ }^{1} \mathrm{H}$ NMR and ${ }^{13} \mathrm{C}$ NMR spectra were measured using Agilent $600 \mathrm{MHz}$ Premium Compact NMR spectrometer in DMSO using TMS as the internal standard.

\section{Synthesis of Compounds}

Synthesis of $\mathbf{2 - c h l o r o - N - a l k y l a c e t a m i d e s ~ ( 1 a - c ) : ~ O c t y l a m i n e , ~ d e c y l a m i n e , ~ d o d e c y l a m i n e ~}$ and chloracetyl chloride compounds used as starting materials in the syntheses were purchased from Merck (Germany). Synthesis of the 2-chloro-N-octyl, -decyl and dodecylacetamide compounds was carried out as previously reported in the literature $(12,13)$.

Synthesis of 2-[(2,3-dihydroxypropyl)sulfanyl]-N-octylacetamide (2a): The procedure used to synthesize this compound was performed in some minor variations, similar to previously reported procedures $(14,15)$. In a round-bottom reaction flask, $0.27 \mathrm{~g}(4.76 \mathrm{mmol})$ of $\mathrm{KOH}$ was dissolved in absolute ethanol, and $0.52 \mathrm{~g}(4.76 \mathrm{mmol})$ of 3-mercapto-1,2-propanediol was added gradually to the reaction flask. The mixture was stirred for about 10 minutes, and then $0.98 \mathrm{~g}$ $(4.76 \mathrm{mmol})$ of 2 -chloro- $N$-octylacetamide (1a) was added slowly to the flask. The reaction mixture was stirred overnight at room temperature. At the end of the reaction, ethanol was evaporated, and the residue was dissolved in dichloromethane and extracted with water. The organic phase was dried over sodium sulfate, and the solvent was removed with a rotary evaporator. The residue was crystallized from petroleum ether/ethyl acetate to give a solid white product. Yield $(0.69 \mathrm{~g}, 52 \%) ; \mathrm{mp} 64-65^{\circ} \mathrm{C}$.

Synthesis of 2-[(2,3-dihydroxypropyl)sulfanyl]-N-decylacetamide (2b): $0.32 \mathrm{~g}$ (5.69 $\mathrm{mmol})$ of $\mathrm{KOH}, 0.62 \mathrm{~g}(5.69 \mathrm{mmol})$ of 3-mercapto-1,2-propanediol and $1.33 \mathrm{~g}(5.69 \mathrm{mmol})$ of 2-chloro- $N$-decylacetamide (1b) were used for the synthesis. The same experimental procedure

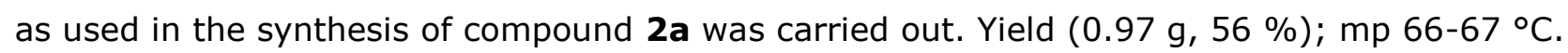


Synthesis of 2-[(2,3-dihydroxypropyl)sulfanyl]-N-dodecylacetamide (2c): $0.43 \mathrm{~g}$ (7.66 $\mathrm{mmol})$ of $\mathrm{KOH}, 0.83 \mathrm{~g}(7.66 \mathrm{mmol})$ of 3-mercapto-1,2-propanediol and $2.0 \mathrm{~g} \mathrm{(7.66} \mathrm{mmol)} \mathrm{of} \mathrm{2-}$ chloro- $N$-dodecylacetamide (1c) were used for the synthesis. The same experimental procedure as used in the synthesis of compound $\mathbf{2 a}$ was carried out. Yield $(2.0 \mathrm{~g}, 79 \%) ; \mathrm{mp} 79-79{ }^{\circ} \mathrm{C}$.

\section{Corrosion Tests Performed in Acidic Media}

\section{Preparations of Coupons and Acidic Solutions}

Gravimetric measurements were performed using the coupons made from cold-rolled low-carbon steel, possessing DIN EN 10130 special conditions (16). Their composition was $0.07 \%$ C, $0.35 \%$ $\mathrm{Mn}, 0.015 \% \mathrm{P}$, and $0.015 \% \mathrm{~S}$. The coupons were cut into rectangular shapes of $0.1 \times 2.2 \times 5.0$ $\mathrm{cm}$ in thickness, width, and length, respectively. Before the immersion test, the coupons were immersed in $15 \% \mathrm{HCl}$, polished lightly with a paper tissue, washed with deionized water and soaked in acetone. $1.0 \mathrm{M} \mathrm{HCl}$ solution was prepared from the concentrated $\mathrm{HCl}(37 \%)$ (Merck grade).

\section{Weight Loss Measurements}

The synthesized cationic surfactants with the concentration of 25, 50, 100, 150 and 250 ppm were tested to determine the inhibition efficiency in $100 \mathrm{~mL}$ of $1.0 \mathrm{M} \mathrm{HCl}$ solution. All the corrosion inhibitors were directly dissolved in the acidic solution. The treatment solutions were poured into $150-\mathrm{mL}$ sealed glass bottles, and the coupons were suspended in these solutions without stirring for $24 \mathrm{~h}$ at room temperature. Control tests were performed in the same way without the inhibitors. After the corrosion test, the coupons were removed, rinsed with water and wiped with paper tissues. Then, they were washed with acetone and dried to a constant weight in an oven $(17,18)$.

\section{SEM}

The carbon steel specimens (of a size of $0.1 \mathrm{~cm} \times 2.0 \mathrm{~cm} \times 2.0 \mathrm{~cm}$ ) were abraded with emery paper and then were washed with distilled water and acetone. They were then immersed in 1.0 $\mathrm{M} \mathrm{HCl}$ solutions containing no inhibitor and containing $250 \mathrm{ppm}$ of the corresponding inhibitor for $24 \mathrm{~h}$ at room temperature. After the immersion time, the steel specimens were cleaned with distilled water and dried in a vacuum desiccator. Finally, the surface images of the steel specimens were obtained from a Carl Zeiss EVO 40 (SEM) device.

\section{RESULTS AND DISCUSSION}

\section{Synthesis of nonionic surfactants}

The synthesis scheme of the designed and synthesized organic nonionic surfactants to test corrosion inhibition in acidic media is given in Scheme 1. As seen in Scheme 1, the synthesis of organic surfactants was carried out in two steps. In the first step, the long-chained amine 
compound was reacted with chloroacetyl chloride in the presence of triethylamine to synthesize 2-chloro-N-alkylacetamides (1a-c). In the second stage, 2-chloro-N-alkyl acetamides (1a-c) were reacted under basic medium with 3-mercapto-1,2-propanediol in alcohol to obtain the nonionic surfactants (2a-c).

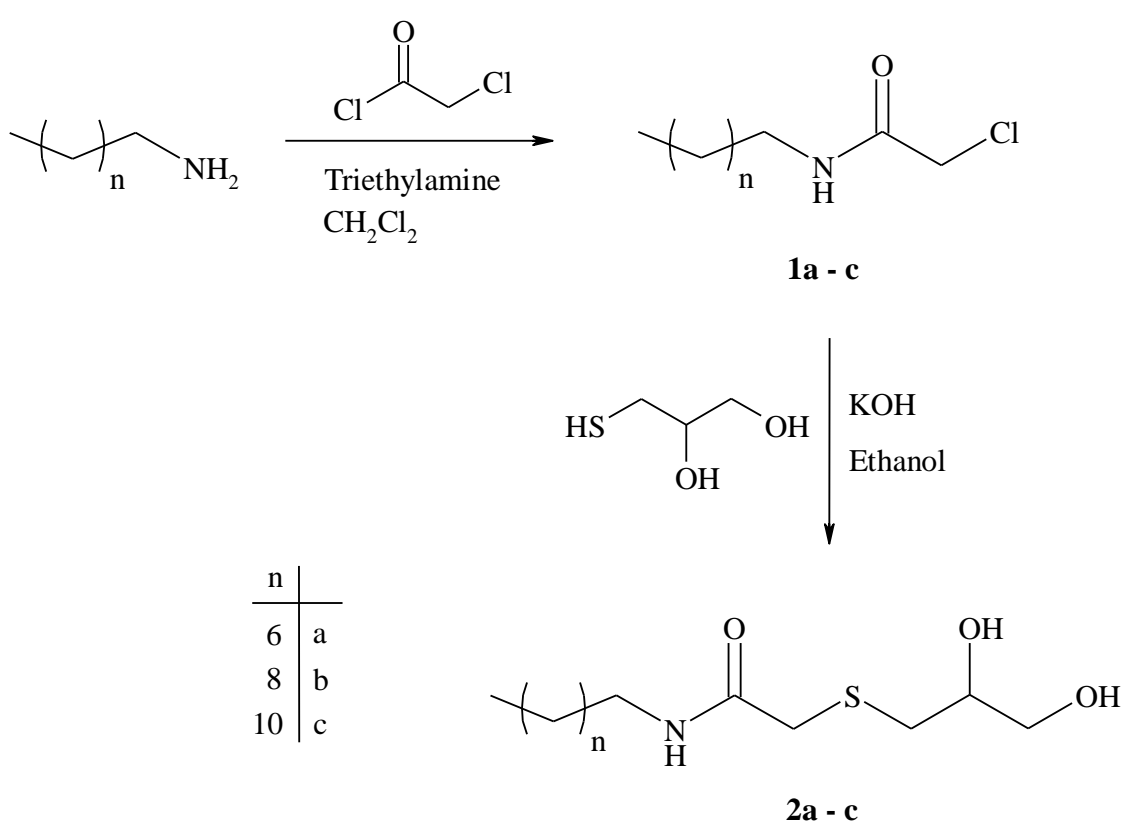

Scheme 1. Synthetic pathways for the preparation of the compounds ( $2 a-c)$.

The structures of the nonionic were confirmed by FT-IR, ${ }^{1} \mathrm{H} N M R$, and ${ }^{13} \mathrm{C}$ NMR spectroscopic methods. The spectral data of $\mathbf{2 a}, \mathbf{2} \mathbf{b}$, and $\mathbf{2} \mathbf{c}$ compounds are shown in Table 1 . FT-IR, ${ }^{1} \mathrm{H}$ NMR and ${ }^{13} \mathrm{C}$ NMR spectra of compound $\mathbf{2} \mathbf{b}$ as spectrum samples are given in Figure 1 . The FT-IR spectra of (2b) showed absorption bands at $3332 \mathrm{~cm}^{-1}$, due to the $-\mathrm{OH}$ groups, at $3266 \mathrm{~cm}^{-1}$, due to the amide $\mathrm{N}-\mathrm{H}$ group, at $1638 \mathrm{~cm}^{-1}$, due to the amide $\mathrm{C}=\mathrm{O}$ group, and at $698 \mathrm{~cm}^{-1}$, due to the $\mathrm{CH}_{2}-\mathrm{S}-\mathrm{CH}_{2}$ group. The ${ }^{1} \mathrm{H}$ NMR spectrum of (2b) showed a triplet peak at $\delta=6.83 \mathrm{ppm}$ for the amide- $\mathrm{NH}\left(\underline{\mathrm{HN}}-\mathrm{CO}\right.$ ) proton, a sextet peak at $\delta=3.85 \mathrm{ppm}$ for the $\mathrm{S}-\mathrm{CH}_{2}-\mathrm{C} \underline{\mathrm{H}}-\mathrm{OH}$ proton. Moreover, and a doublet peak at $\delta=3.70 \mathrm{ppm}$ is observed for the $\mathrm{S}-\mathrm{CH}_{2}-\mathrm{CH}-\mathrm{OH}$ proton. Also, a doublet peak at $\delta=3.68 \mathrm{ppm}$ for the $\underline{\mathrm{HO}}-\mathrm{CH}_{2}-\mathrm{CH}-\mathrm{OH}$ proton, a singlet peak at $\delta=3.26 \mathrm{ppm}$ for the $\mathrm{HN}-\mathrm{CO}-\mathrm{C}_{2}-\mathrm{S}$ protons and a quartet peak at $\delta=3.24 \mathrm{ppm}$ for the $\mathrm{C}_{2}-\mathrm{HN}-\mathrm{CO}$ protons were observed. The peak attributed to the $\mathrm{HN}-\mathrm{CO}-\mathrm{CH}_{2}-\mathrm{S}$ protons at $3.26 \mathrm{ppm}$ is the evidence that the nucleophilic substitution reaction between $\mathbf{1 b}$ and 3-mercapto-1,2-propanediol was successfully actualized. The formation of the compound $\mathbf{2} \mathbf{b}$ has been proved by the peak showed at $36.24 \mathrm{ppm}$ for the carbon atom in the ${ }^{13} \mathrm{C}$ NMR spectrum. 
Table 1. Spectral data of compound $\mathbf{2 a ,} \mathbf{2} \mathbf{b}$ and $\mathbf{2 c}$.

\begin{tabular}{|c|c|}
\hline Compound & pectral Data \\
\hline $2 a$ & 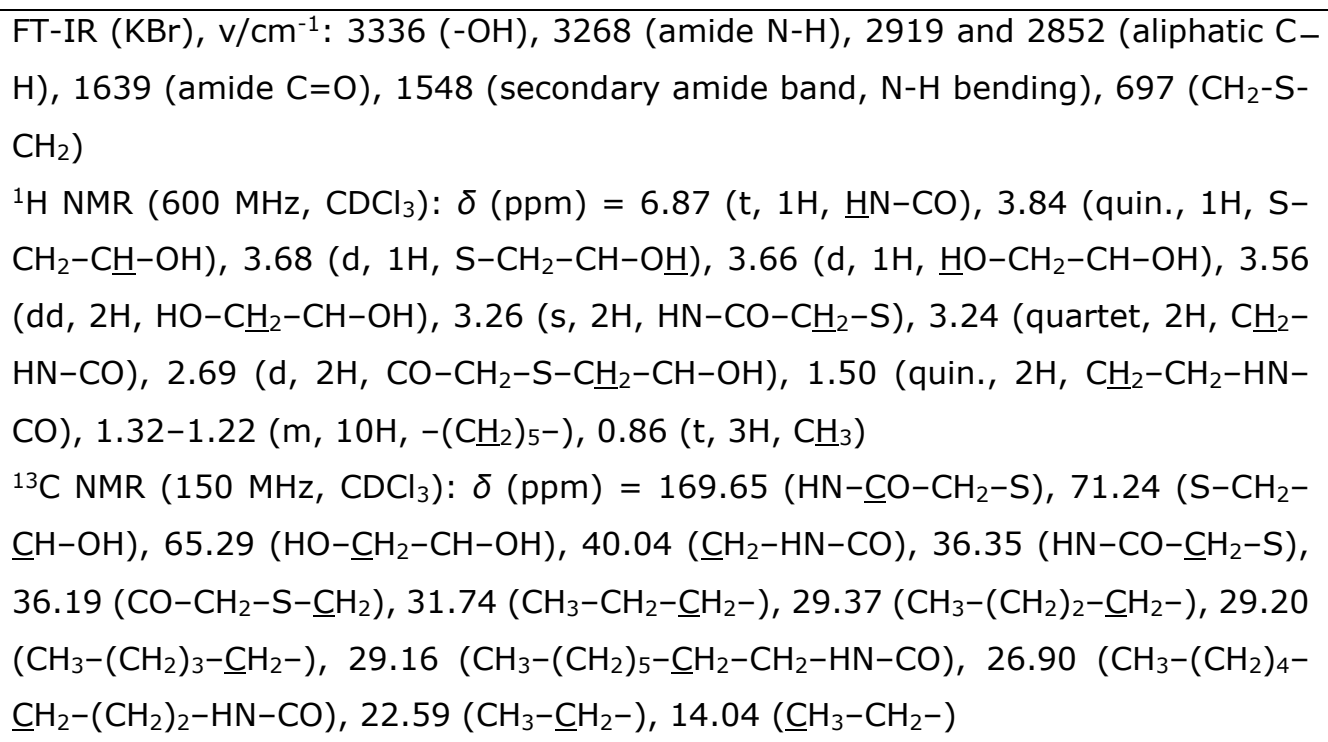 \\
\hline $2 b$ & 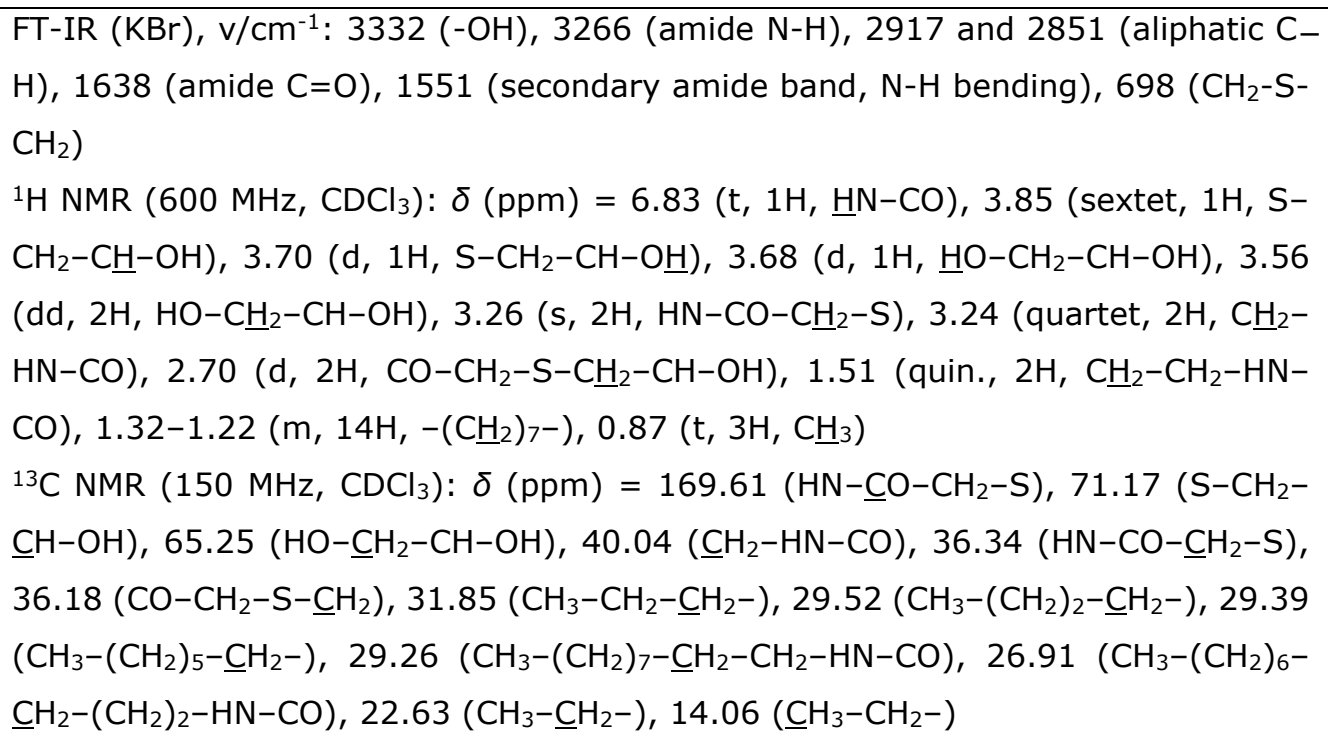 \\
\hline $2 c$ & 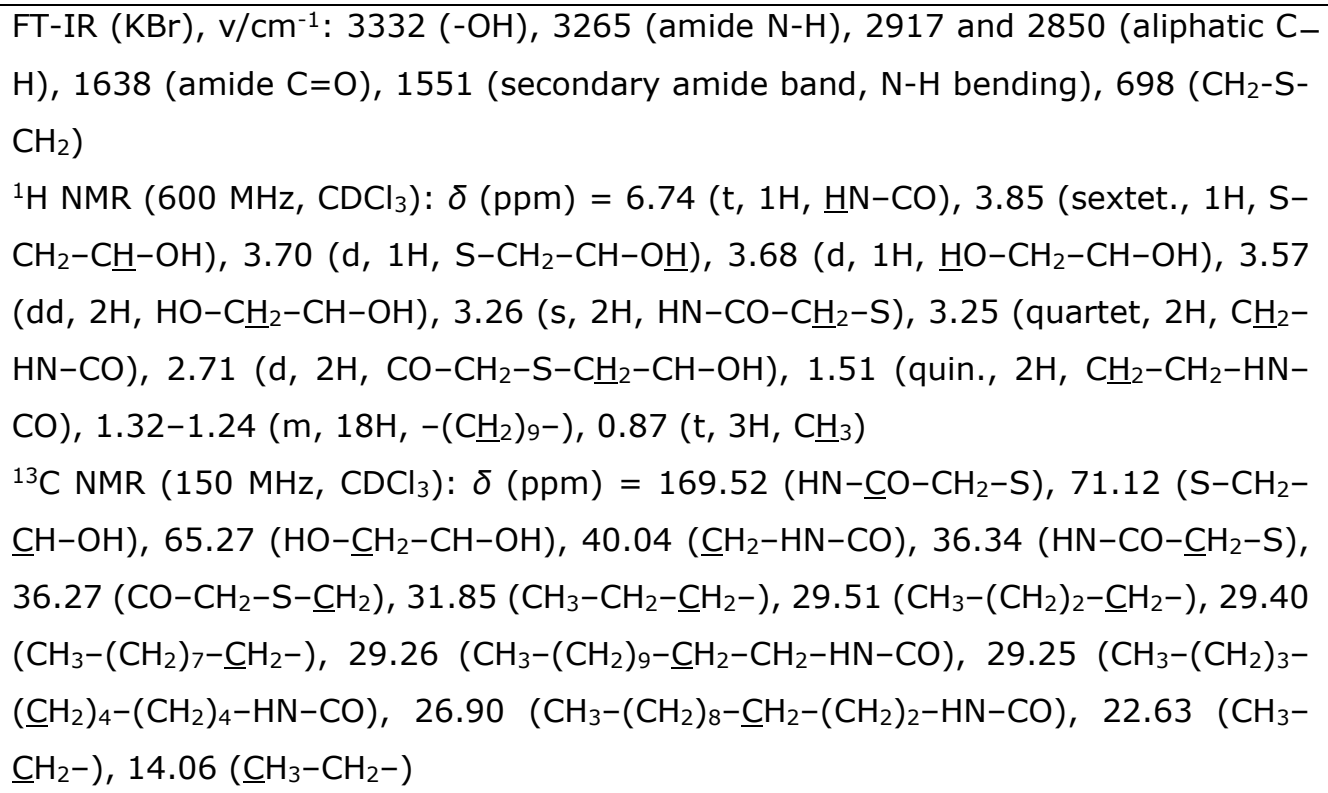 \\
\hline
\end{tabular}



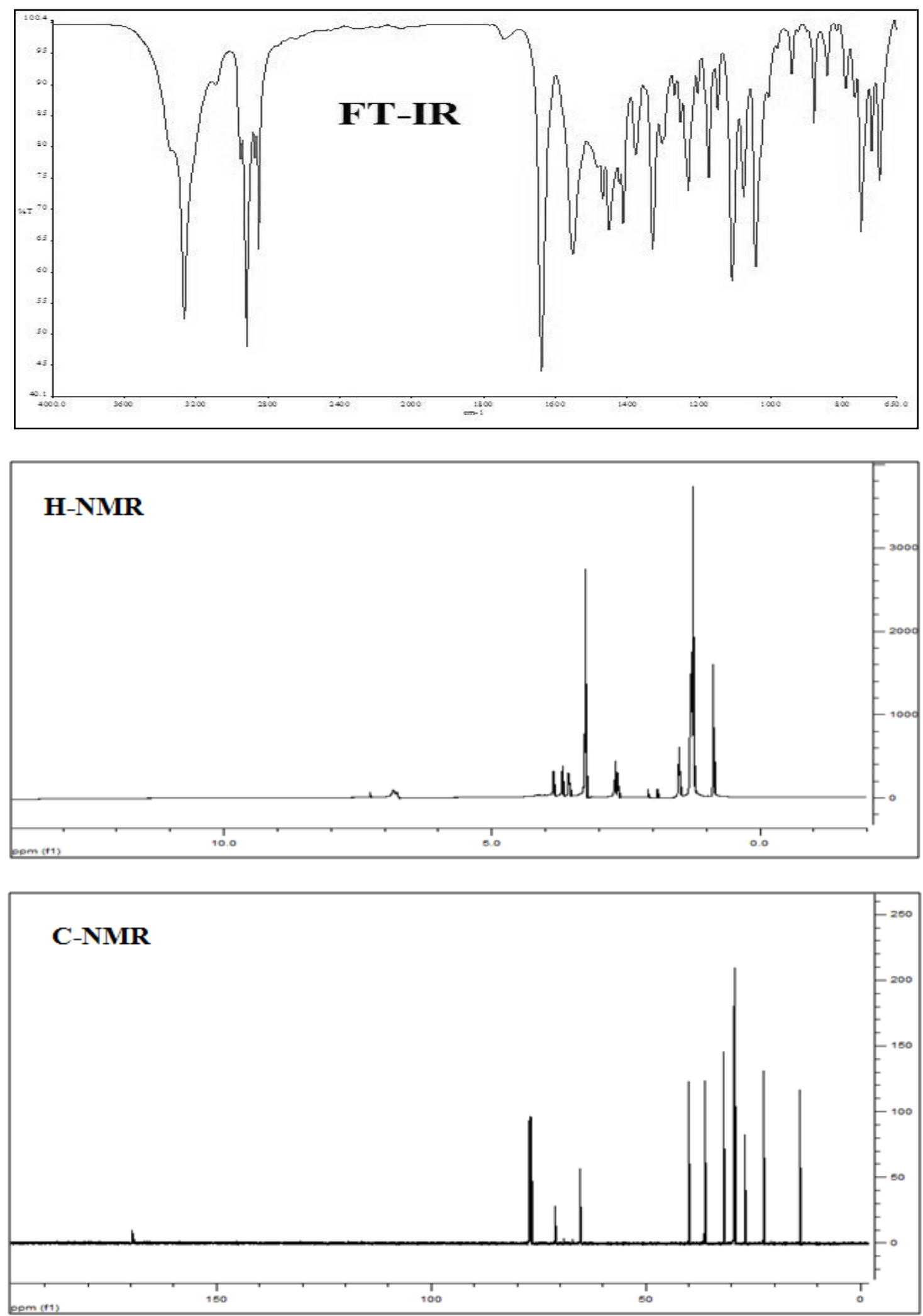

Figure 1. $\mathrm{FT}-\mathrm{IR},{ }^{1} \mathrm{H}$ NMR and ${ }^{13} \mathrm{C}$ NMR spectra of (2b).

\section{Corrosion tests in acidic media}

Corrosion tests in acidic media $(1.0 \mathrm{M} \mathrm{HCl})$ were performed using weight loss measurements according to the ASTM NACE / ASTMG31-12a standard method (19). The corrosion test results of the synthesized $\mathbf{2 a}$-c surfactants in $1.0 \mathrm{M} \mathrm{HCl}$ corrosive media are shown in Table 2 . In the 
corrosion tests, corrosion inhibitors were directly dissolved in the acid solution. Corrosion inhibition capabilities of the synthesized compounds tested in $1.0 \mathrm{M} \mathrm{HCl}$ are given as percentage inhibition efficiencies (IE \%). Percentage inhibition efficiencies were calculated using the following Eq. 1:

$$
\text { IE } \%=\frac{\text { Wo-W }}{\text { Wo }} \times 100
$$

Where (IE \%) is the percentage inhibition efficiency, $W_{0}$ is the weight loss of the coupon in the absence of an inhibitor and $W$ is the weight loss of the coupon in the same environment in the presence of an inhibitor. The corrosion rate (CR) values that are given in Table 2, are derived from Eq. 2 (20-22):

$$
\mathrm{CR}=\frac{\Delta \mathrm{W}}{\mathrm{At}}
$$

where $\Delta \mathrm{W}$ is the weight loss $(\mathrm{mg}) ; \mathrm{A}$ is the area of the coupon $\left(\mathrm{cm}^{2}\right)$, and $\mathrm{t}$ is the immersion time (h).

Table 2 Weight loss, corrosion rate and corrosion inhibition efficiencies (IE \%) for varying

\begin{tabular}{|c|c|c|c|c|c|c|c|c|c|}
\hline \multirow[t]{2}{*}{$\begin{array}{l}\text { Concentration } \\
\text { (ppm) }\end{array}$} & \multicolumn{3}{|c|}{$\begin{array}{l}\text { Weight loss } \\
\left(\mathrm{mg} \mathrm{cm}^{-2}\right)^{*}\end{array}$} & \multicolumn{3}{|c|}{$\begin{array}{c}\text { Corrosion Rate } \\
\left(m g \mathrm{~cm}^{-2} \mathrm{hr}^{-1}\right) \\
\times 10^{-2}\end{array}$} & \multicolumn{3}{|c|}{$\begin{array}{c}\text { Inhibition Efficiency } \\
\text { (IE \%) }\end{array}$} \\
\hline & $2 a$ & $2 b$ & $2 c$ & $2 a$ & $2 b$ & $2 c$ & $2 a$ & $2 b$ & $2 c$ \\
\hline 0 & 12.50 & 12.50 & 12.50 & 52.08 & 52.08 & 52.08 & - & - & - \\
\hline 25 & 2.93 & 1.12 & 1.25 & 12.20 & 4.66 & 5.19 & 76.58 & 91.05 & 90.04 \\
\hline 50 & 2.32 & 1.04 & 0.90 & 9.66 & 4.32 & 3.75 & 81.45 & 91.71 & 92.80 \\
\hline 100 & 1.42 & 0.93 & 1.07 & 5.91 & 3.86 & 4.47 & 88.65 & 92.58 & 91.42 \\
\hline 150 & 1.35 & 0.91 & 1.24 & 5.61 & 3.79 & 5.15 & 89.24 & 92.73 & 90.11 \\
\hline 250 & 0.78 & 0.85 & 0.83 & 3.26 & 3.52 & 3.45 & 93.74 & 93.24 & 93.38 \\
\hline
\end{tabular}
concentrations of compounds $\mathbf{2 a}-\mathbf{c}$ in $1.0 \mathrm{M} \mathrm{HCl}$ medium for $24 \mathrm{~h}$ at room temperature.

* Mean of the two measured values

When Table 2 is examined, it can be seen that at high concentrations, the three surfactants exhibit perfect inhibition activity. The corrosion resistance of the three compounds at $250 \mathrm{ppm}$ inhibitor concentration was almost the same. However, it has been found that the inhibitory actions of compounds $\mathbf{2} \mathbf{b}$ and $\mathbf{2} \mathbf{c}$ are close to each other in all studied inhibitor concentrations. Furthermore, compound $\mathbf{2 a}$ showed lower corrosion inhibition activity at lower levels than compounds $\mathbf{2} \mathbf{b}$ and $\mathbf{2 c}$. The order of inhibition efficiency of these compounds is related to the molecular size of surfactant molecules. The long carbon chain of compound $\mathbf{2 a}$ is shorter than the other two compounds. Higher molecular size tends to increase the adsorption on the metal 
surface and hence to result in more surface coverage (23). With this more surface coverage, more effective protection against corrosion is achieved, especially at low concentrations. However, as the inhibitor concentration increases, the increase in inhibition activity is an expected result. It is proven that the inhibition efficiency increases with the increasing of inhibitor concentration. On the other hand, as seen in Table 2, the weight loss and corrosion rates in the inhibitor medium are considerably lower than in the uninhibited environment. The decrease in weight loss in the presence of inhibitors is due to the adsorption of the nonionic surfactants onto the carbon steel surface, forming a protecting layer, which leads to the increase in the coverage metal area. This adsorption of inhibitors decreases the contact between the metal surface and the aggressive medium. Therefore, this fall the corrosive effect of aggressive medium on the metal surface (24). All these results demonstrate that the synthesized nonionic surfactants are effective against metal corrosion.

\section{SEM}

Surface analysis with scanning electron microscopy is essential concerning the interaction of organic molecules with the metal surface and the observation of the morphological changes occurring on the surface of the metal. As for this purpose, scanning electron microscopic images were recorded to verify the interaction of the synthesized nonionic surfactants with the metal surface (Figure 2). The SEM image of Figure 2a, which was taken from the 1,000 x magnified surface, shows the feature of the steel surface after immersion in $1.0 \mathrm{M} \mathrm{HCl}$ at room temperature for $24 \mathrm{~h}$ in the absence of inhibitor. Figures $2 \mathrm{~b}, 2 \mathrm{c}$ and $2 \mathrm{~d}$ show the properties of the steel surface after immersion in $1.0 \mathrm{M} \mathrm{HCl}$ containing $250 \mathrm{ppm}$ of inhibitor. As seen in Figure 2a, wear was observed on the entire surface of the metal exposed to the acid environment without the inhibitor. It is clear that corrosion products are accumulated on the metal surface due to corrosion, and therefore the surface becomes rough. On the other hand, there is no wear or roughness on the metal surfaces exposed to the inhibitor-containing acid environment. The scratch marks on the metal surfaces are due to the sanding process made before the test. This proves that the inhibitor molecules are adsorbed to the metal surface and protect the surface against corrosion in $\mathrm{HCl}$ media. As a result, the metal surface images obtained from the SEM device support the high inhibition activity results given in Table 2.

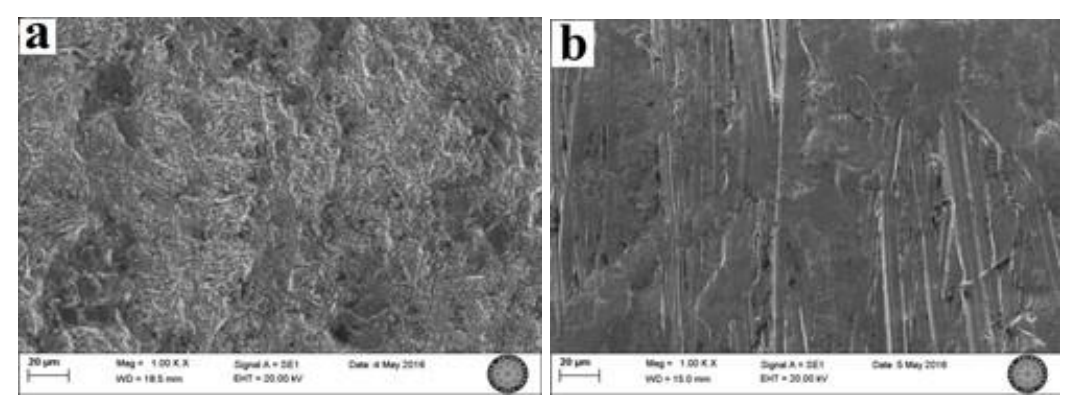



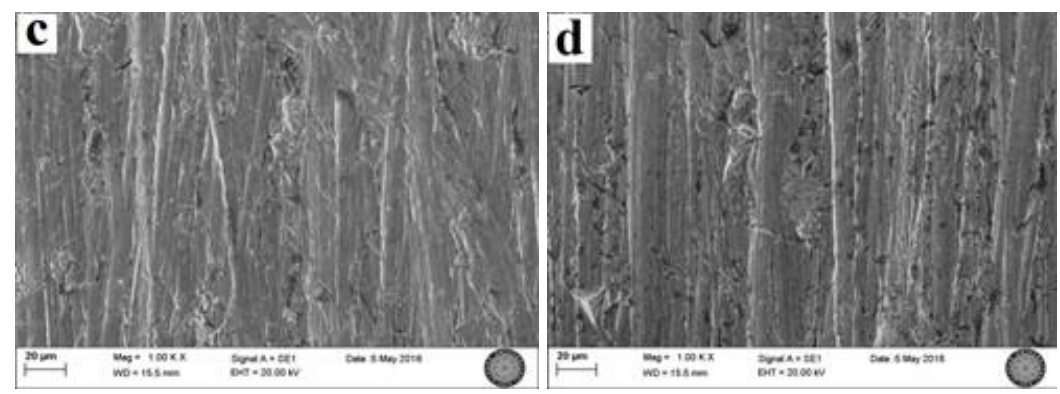

Figure 2. SEM images of the metal coupon surfaces immersed in $1.0 \mathrm{M} \mathrm{HCl}$ for $24 \mathrm{~h}$. a without inhibitor 1,000x, b 250 ppm (2a) 1,000x, c 250 ppm (2b) 1,000x, d 250 ppm (2c) 1,000x

\section{Corrosion inhibition mechanism}

The first step in the mechanism of action of surfactant molecules as corrosion inhibitors is the adsorption onto the metal surface. The adsorption process is influenced by the nature and the surface charge of the metal, the chemical structure of the surfactant, the type of surfactant and the kind of the corrosive medium. The inhibition efficiency of nonionic surfactant molecules is related to the surfactant's ability to associate with one another at interfaces and in solution to aggregate to form micelles (23). In the nonionic surfactants, the driving force of micellization is the hydrophobic force and van der Waals attractions. The strong interaction between water molecules repels the hydrocarbon chain from the water bulk phase. It causes the non-polar hydrophobic groups to be directed away from the water molecule with the aid of polar hydrophilic groups in the molecule. Thus, at lower concentrations, it is expected that micelle formation will occur for extended chain surfactants (9). As can be seen in Table 2, the close inhibitory activity of compounds $\mathbf{2} \mathbf{b}$ and $\mathbf{2} \mathbf{c}$ in each studied concentration can be explained by this micellar formation and critical micelle concentration (CMC). It is known that nonionic surfactants may form micelles at lower levels than ionic surfactants and have lower CMCs $(3,25)$. The gathering of surfactants as micelles at low concentrations causes to more adsorption on the metal surface and hence a more efficient inhibition at lower levels (23). When surfactants form micelles and reach the $\mathrm{CMC}$, the inhibition efficiency of these compounds, which are very similar to each other, is very close to each other and does not change much with increasing concentrations. The inhibition efficiencies obtained for compounds $\mathbf{2} \mathbf{b}$ and $\mathbf{2} \mathbf{c}$ are a result of this phenomenon.

Apart from micelle formation, the mechanism of adsorption of nonionic surfactant molecules at metal/solution interfaces can also be governed by the following factors (23):

- The interaction between the lone pair of electrons located in p-orbitals in the inhibitor molecules and the vacant metal orbitals.

- The interaction between uncharged moieties in the inhibitor molecules and the metal surface. 
When the structures of the synthesized nonionic surfactants are examined, the following points were observed:

- There are two hydroxyl groups to facilitate dissolution in water.

- There are N, O and S heteroatoms in their structure. Through these heteroatoms, they adsorb onto the metal surface by chemical adsorption and reduce the adverse effect of the acidic corrosive environment on the metal surface by closing the active centers on the surface.

- They contain a hydrophobic group (long carbon chain) which prevents the contact of the corrosive environment with the metal surface. The long carbon chain pushes water molecules and prevents the acidic aqueous solution from approaching the surface. However, the long alkyl chains enter a non-polar interaction with each other due to the van der Waals attraction forces, and as a result of this interaction, they provide more effective protection on the metal surface against the corrosive medium.

The orientations of the inhibitor molecules at the metal-acidic solution interface and the possible inhibition mechanism are shown in Figure 3. As seen, molecules are found in an upright position in the metal surface which provides maximum protection. Primarily, to form bilayer or multimolecular layers, the hydrophobic tail of the surfactant molecule is oriented perpendicularly to the metal surface. The van der Waals interactions (non-polar physical interaction) occurring between the long alkyl chains in this perpendicular position are shown in Figure 3. These layers, designated as protective layers, behave as a barrier between the metal and the corrosive medium (18).

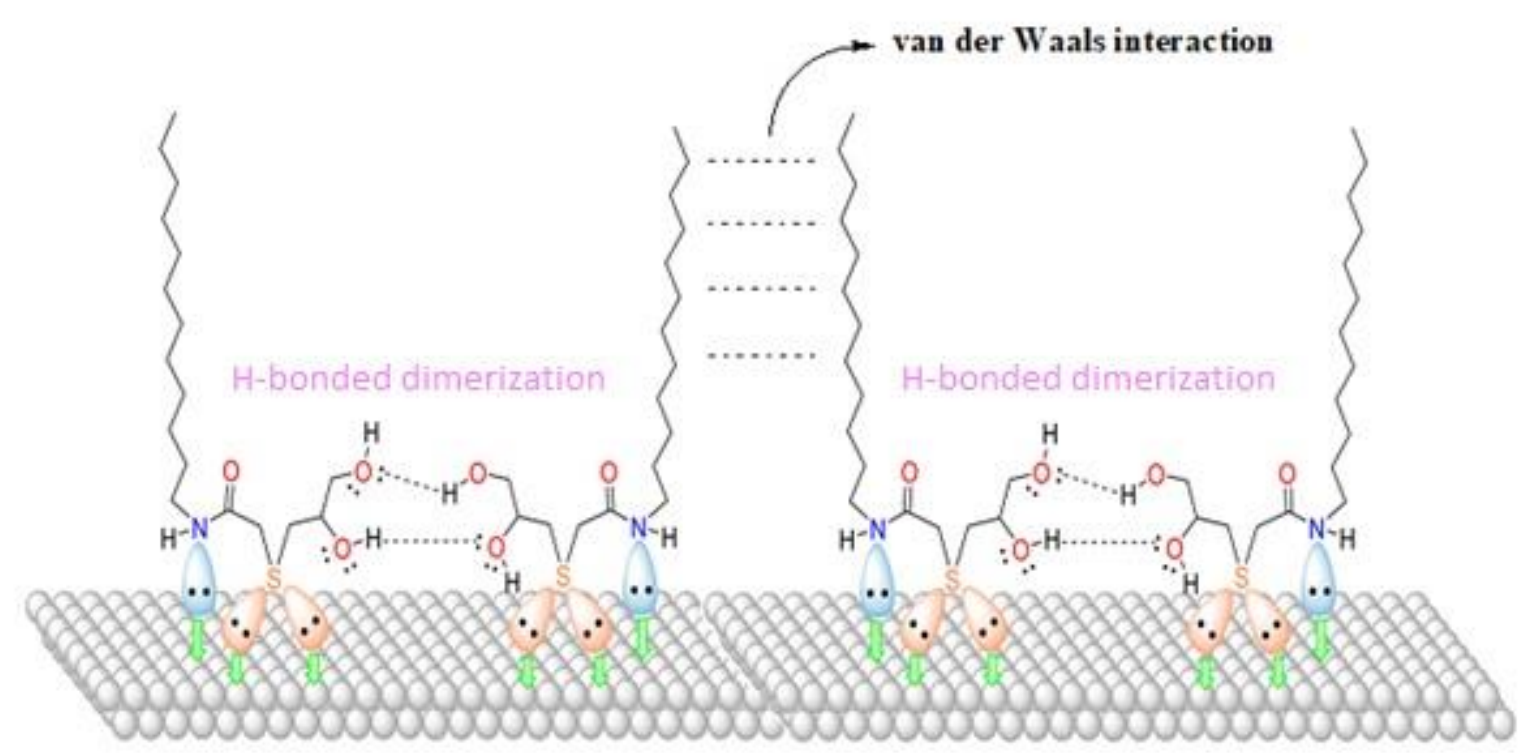

Figure 3. A possible orientation of non-ionic surfactant molecules between the metal-acidic solution interfaces.

In Figure 3, it can also be seen that nonionic surfactant molecules are adsorbed onto the metal surface via $\mathrm{N}$ and $\mathrm{S}$ heteroatoms by chemical adsorption. The chemical adsorption occurs from 
the donor-acceptor interaction between $\mathrm{p}$ electrons of donor atoms ( $\mathrm{N}$ and $\mathrm{S}$ ) of the inhibitors and the vacant d-orbitals of iron surface atoms. Through this chemical adsorption, coordination bonds occur between the heteroatom and iron $(26,27)$. Sulfur and nitrogen atoms can form a protective layer (through coordination bonds between these heteroatoms and metal atoms), which covers the entire surface quickly and blocks the access to the active site of corrosion on the surface (9). Besides, intermolecular $\mathrm{H}$-bonds are formed via hydroxyl groups, which increase the stability of the protective layer. It has been reported that the $\mathrm{pH}$ can influence this intermolecular interaction between hydroxyl groups of nonionic surfactants. At neutral $\mathrm{pH}$, these intermolecular interactions and hence the adsorption to the metal surface of the synthesized nonionic surfactants are low, but it is increased at lower $\mathrm{pH}$ values (28). Furthermore, the formation of the hydrogen bond and the van der Waals interactions between the hydrophobic groups increase with an increase of the inhibitor concentration. It, therefore, leads to better protection of the metal surface and increased the inhibition efficiency of the nonionic surfactants $(29,30)$.

\section{CONCLUSIONS}

2,3-dihydroxypropyl-sulfanyl derivatized three nonionic surfactants containing high carbon chained amide functional group were synthesized as potential corrosion inhibitors for mild steel in $1.0 \mathrm{M} \mathrm{HCl}$ acidic media. From the results, we can conclude the following:

- All the nonionic surfactants exhibited good corrosion inhibition at high inhibitory concentrations.

- The corrosion inhibition efficiencies of the synthesized compounds increased with the increase in the inhibitory concentration.

- In the corrosion inhibition mechanism, the adsorption of the synthesized nonionic surfactants to the metal surface was performed with the help of micellar formation, chemical adsorption and physical adsorptions (intermolecular H-Bonds between hydroxyl groups and van der Waals interaction between the hydrophobic groups of the nonionic surfactants).

- The SEM images supported the inhibition results obtained by weight loss measurements.

\section{CONFLICT OF INTEREST}

The authors declare no conflict of interest.

\section{REFERENCES}

1. Görenler A. Al-Si Matrisli Kompozit Malzemelerin Korozyon Davranışlarının İncelenmesi. Yıldız Teknik Üniversitesi, Fen Bilimleri Entüsü, Yüksek Lisans Tezi, 2007 İstanbul.

2. Bereket G, Pinarbasi A. Inhibition effect of some heterocyclic compounds on pure aluminium in $0.1 \mathrm{M}$ hydrochloric acid solution. Corrosion. 2008 16: 17-22. 
3. Shaban S M, Abd-Elaal A A, Tawfik S M. Gravimetric and electrochemical evaluation of three nonionic dithiol surfactants as corrosion inhibitors for mild steel in $1 \mathrm{M} \mathrm{HCl}$ solution. J. Mol. Liq. $2010 \mathrm{Apr}$; 216:392-400.

4. Yıldırım A, Çetin M. Synthesis and evaluation of new long alkyl side chain acetamide, isoxazolidine and isoxazoline derivatives as corrosion inhibitors. Corros Sci. 2008 Jan; 50:155-65

5. Negm N A, Kandile N G, Badr E A, Mohammed M A. Gravimetric and electrochemical evaluation of environmentally friendly nonionic corrosion inhibitors for carbon steel in $1 \mathrm{M} \mathrm{HCl}$. Corros. Sci. $2012 \mathrm{Dec}$; 65:94-103.

6. Hegazy M A, El-Tabei A S, Ahmed H M. Synthesis of nonionic surfactants and their inhibitive action on carbon steel in hydrochloric acid. Corros.Sci. 2012 Nov; 64:115-25

7. El-Tabei A S, Hegazy M A. A corrosion inhibition study of a novel synthesized gemini nonionic surfactant for carbon steel in $1 \mathrm{M} \mathrm{HCl}$ solution. J. Surfact. Deterg. 2013 Sep;16:757-66.

8. Sobhi M, El-Sayed R, Abdallah M. Synthesis, surface properties, and inhibiting action of novel nonionic surfactants on carbon steel corrosion in $1 \mathrm{M}$ hydrochloric acid solution. Chem. Eng. Commun. 2016; 203:758-68.

9. Fuchs-Godec R. Inhibitory effect of non-ionic surfactants of the Triton-X series on the corrosion of carbon steel in sulphuric acid. Electrochim. Acta 2007 Apr; 52:4974-81.

10. Hegazy M A, Zaky M F. Inhibition effect of novel nonionic surfactants on the corrosion of carbon steel in acidic medium. Corros. Sci. 2010 Apr; 52:1333-41.

11. Mobin M, Zehra S, Parveen M. L-Cysteine as corrosion inhibitor for mild steel in $1 \mathrm{MHCl}$ and synergistic effect of anionic, cationic and non-ionic surfactants, J. Mol. Liq. 2016 Apr; 216:598-607.

12. Van Esch J H, Hoffmann M M, Nolte R J M. Reduction of nicotinamides, flavins, and manganese porphyrins by formate, catalyzed by membrane-bound rhodium complexes. J. Org. Chem. 1995 Mar; 60:1599-1610.

13. Maksoud SAAE (2004) The effect of hexadecyl pyridinium bromide and hexadecyl trimethyl ammonium bromide on the behaviour of iron and copper in acidic solutions. J. Electroanal. Chem. 2004 Apr; 565:321-8.

14. Morris-Natschke S L, Gumus F, Marasco C J, Meyer K L, Marx M, Piantadosi C, Layne M D, Modest E J. Synthesis of phosphocholine and quaternary amine ether lipids and evaluation of in vitro antineoplastic activity. J. Med. Chem. 1993 Jul; 36:2018-25.

15. Alexander R L, Morris-Natschke S L, Ishaq K S, Fleming R A, Kucera G L. Synthesis and cytotoxic activity of two novel 1-dodecylthio-2-decyloxypropyl-3-phosphatidic acid conjugates with gemcitabine and cytosine arabinoside. J. Med. Chem. 2003 Sep; 46:4205-8.

16. Anonim. Cold rolled low carbon steel flat products for cold forming - Technical delivery conditions; German version EN 10130:2006, DIN Deutsches Institut für Normung e. V., 14s., 2007, Berlin, Germany.

17. Öztürk S, Yıldırım A, Çetin M, Tavaslı M. Synthesis of quaternary, long-chain N-alkyl amides and their corrosion inhibition in acidic media. J. Surfact. Deterg. 2014 May; 17: 471-81.

18. Yıldırım A, Öztürk S, Çetin M. Novel amide-based cationic surfactants as efficient corrosion inhibitors for carbon steel in $\mathrm{HCl}$ and $\mathrm{H}_{2} \mathrm{SO}_{4}$ media. J. Surf. Deterg. 2013 Jan; 16:13-23.

19. ASTM NACE / ASTMG31-12a, Standard Guide for Laboratory Immersion Corrosion Testing of Metals, ASTM International, West Conshohocken, PA, 2012 Oct; p.10.

20. Okoronkwo A E, Olusegun S J, Oluwasina O O. The inhibitive action of chitosan extracted from Archachatina marginata shells on the corrosion of plain carbon steel in acid media. Anti. Corros. Method M. 2015; 62:13-8.

21. Mohamed H A, Rehim, M H A. Surface active hyperbranched polyamide-ester as a corrosion inhibitor for carbon steel in both neutral and acidic media. Anti. Corros. Method M. 2015; 62:95-102. 
22. Lashgari M, Arshadi M R, Biglar M. Comparative studies of some heterocyclic compounds as corrosion inhibitors of copper in phosphoric acid media. Chem. Eng. Commun. 2010; 197:1303-14.

23. Sobhi M, El-sayed $R$, Abdallah $M$. The effect of non ionic surfactants containing triazole, thiadiazole and oxadiazole as inhibitors of the corrosion of carbon steel in $1 \mathrm{M}$ hydrochloric acid. J. Surfact. Deterg. 2013 Nov; 16:937-46.

24. Shaban SM, Aiad I, El-Sukkary MM, Soliman EA, El-Awady MY. Inhibition of mild steel corrosion in acidic medium by vanillin cationic surfactants. J. Mol. Liq. 2015 Mar; 203:20-8.

25. Fuchs-Godec R, Pavlovic MG. Synergistic effect between non-ionic surfactant and halide ions in the forms of inorganic or organic salts for the corrosion inhibition of stainless-steel $\mathrm{X} 4 \mathrm{Cr} 13$ in sulphuric acid, Corros. Sci. 2012 May; 58:192-201.

26. Athareh D, Fatemeh B. A new synthesized corrosion inhibitor for mild steel in $0.5 \mathrm{M} \mathrm{H}_{2} \mathrm{SO}_{4}$. Gazi University Journal of Science (GU J Sci). 2011; 24:219-26.

27. Tawfik SM, Negm NA. Vanillin-derived non-ionic surfactants as green corrosion inhibitors for carbon steel in acidic environments. Res. Chem. Intermed. 2016 Apr; 42:3579-607.

28. Paria S, Khilar KC. A review on experimental studies of surfactant adsorption at the hydrophilic solidwater interface. Adv. Colloid Interface Sci. 2004 Aug; 110:75- 95.

29. Ramachandran S, Jovancicevic V. Molecular modeling of the inhibition of mild steel carbon dioxide corrosion by imidazolines. Corrosion. 1999 Jun; 55:259-67.

30. Mahmoud S S, Ahmed M M, Marie A H, El-Kasaby R A. Pitting Corrosion Inhibition of Some Copper Alloys in Neutral Solutions by Straight Chain Carboxylates. Portugaliae Electrochim. Acta. 2007; 25:45370. 